\title{
Optimization of VFD Operations for Transporting Equipment of Packages
}

\author{
Lione Urmoniene $^{1,2, *}$, Jelena Dikun ${ }^{2,3}$, Jolanta Januteniene ${ }^{1}$ \\ ${ }^{I}$ Department of Engineering, Klaipeda University, \\ Bijunu St. 17, LT-91225 Klaipeda, Lithuania \\ ${ }^{2}$ Klaipeda State University of Applied Sciences, \\ Bijunu St. 10, LT-91225 Klaipeda, Lithuania \\ ${ }^{3}$ Lithuanian Maritime Academy, \\ Kanto St. 7, LT-92123 Klaipeda, Lithuania \\ lione.urmoniene@ku.lt
}

\begin{abstract}
This study is focused on the efficiency of automated transferring system of packages equipped by variable-frequency drive (VFD) and servo drive motor. It was found that rotation frequency of induction motors and linear speed of servo drive decisively affected the unit efficiency that operates in the periodic mode. The system duty cycle was divided in two separate parts taking into account time spans needed to complete the specific tasks by each separate equipment of the system. In order to reduce the power usage of the system, the duration of each part of cycle was extended. Lowered electricity consumption leads to the extension of each cycle's stage operating times. Frequencies of motors and linear speed of servo drive motors were optimized depending on cycle stages duration. Optimized frequency and linear speed values were calculated and loaded into motors controllers, and the efficiency of each separate equipment was measured, as well as total efficiency of the system. Experimental system debugging using optimized parameters proved that system efficiency increases up to $60 \%$, and that is closely matched with calculated values.
\end{abstract}

Index Terms-Energy consumption; Automation; Variable speed drives; Electric motors.

\section{INTRODUCTION}

Variable frequency drives (VFDs) are widely applied in many common industrial machineries, such as fans, compressors, and pump systems [1]. Many scientific studies and experiments unconditionally confirm the benefits of VFD implementation in the Heating, Ventilation, and Air Conditioning (HVAC) systems. Use of VFD contributes to electrical energy conservation at around $18.3 \%-47.1 \%$ and $36.3 \%-51.7 \%$ in air conditioning systems in winter and summer time, respectively, and it is more economical than a constant speed converter [2]. Another group of scientists [3] found out that energy savings with VFD reached $45 \%$ in the air conditioning systems. As for the pump, fans, blowers, and compressor drives, the energy savings due to application of VDF can vary from $20 \%$ to $70 \%$ [4], [5].

Nevertheless, there are many new scientific investigations addressed to the efficiency enhancements in the systems controlled by VDF [6], [8] that are comprised of inductive motor and logic controller. Efficiency optimization study [6]

Manuscript received 8 June, 2020; accepted 3 January, 2021. suggests focusing attention on the constituent parts of variable frequency drive, especially in lowering the losses in the induction motor. Decrease in rotation speed to $30 \%$ due to VFD in the system of two parallel operating pumps has shown the reduction in consumer power. Reduction up to $66 \%$ of each motor results in energy consumption reduction by $20 \%$ in the system [8]. Power losses elimination in the induction motor [9]-[11], as well as in the drive controlling equipment [7], [11], [13], is of great interest to investigators trying to achieve higher electricity conservation. In work [10], energy efficiency improvement was attained by replacing the inductive motor with permanent magnet motor that results current reducing and allows diminishing annual electricity consumption in installation drive equipment up to $26 \%$. In study [11], investigators minimized power losses by controlling the flux level in the variable load induction motor up to about $60 \%$ using appropriate drive controlling methods. Nevertheless, described methods involve a complex mathematical computation and have a noise that affects measurement accuracy. Another way, described in [12], to improve VFD efficiency deals with induction motor power factor correction by connecting capacitance in parallel to the motor that leads to the efficiency enchanting in the transmission network Motor-PLC-VFD. Such technique results in the power factor correction from 0.693 0.72 up to $0.96-0.98$.

For the higher drive efficiency, different control algorithms (Genetic Algorithm, Particle Swarm Optimization algorithm, Fuzzy Logic and Artificial Neural Network) were used [11]. Although the application of some mentioned algorithms has shown efficiency increasing up to $60 \%$, further investigations of applicability should be continued. In manuscript [7], inductive motor flux was regulated by using Artificial Neural Network control algorithm that indicates satisfactory efficiency results of $18 \%$ for motor operation under steady state conditions. However, the applied control technique was unable to degrade energy losses when the motor was loaded less than $60 \%$ of rated load. In study [13], power loss in induction motor was decreased up to $50 \%$ by controlling the flux by using Genetic Algorithm and Fuzzy Genetic Algorithms in programmable logic controller (PLC). 
Additional power losses occur in the working transferring systems, such as valves and pipes. Moreover, efficiency optimization methods that were described above require a lot of mathematical calculations and technically sophisticated equipment. Additionally, the programmable equipment has to be reinstalled for every new use of controlling algorithm. All these disadvantages make hard to provide an efficiency optimization probe in the specific VDF. Thus, the new investigations in the VDF efficiency optimization are important and still extremely relevant.

Modern scientific research paid insignificant attention to the automation systems equipped by VDF and their efficiency analysis, evaluation, and optimization [20]. Authors state that nowadays there is no unified and satisfactory method for motor's efficiency evaluation used everywhere in the automated industry. Most automation systems are arranged by VFDs that are operating in periodical modes. It means that motors in the VFD operate in the defined duty or load cycles. Generally, transporting equipment of packages includes several VFD drives that operate with different duty cycles. To increase energy consumption of the described automation system, it was decided to extend the stop times of motors because the motor duty cycle includes the ratio of running time to the sum of running and stopping times. Operational time duration of all system's constituents was measured using computer software. The stop time duration was obtained from different types of packages within two hours of incessant operation of the automation line using a programmable logic controller that was connected to each drive of equipment. The electricity expenditures were measured by connecting the measuring leads to the feeders of induction motors, variable frequency drives, and the feeder of servo drive's controller. This was done when the heaviest package was transferred to evaluate the energy consumption under the condition of largest motor's load. Duration of each cycle step was measured separately from the others by running motors in automated modes and returning them to the initial position manually.

Load cycle of the motor is the main VFD parameter that allows reaching the best efficiency. Duty cycles of each motor consist of drive run and stop times that vary periodically [14]. The duration of run and stop times is different and depends on the aims of technological process to be done by the system [15]. The cyclical operation of motor in the periodically repeating stop/run modes allows managing the load on the motor shaft that leads to VDF efficiency, which increases because during motor stop time the power is not consumed by motor from the grid [16]. Presented study focuses on the VFD optimization based on the changes of motor load cycles, as well as finding optimal frequencies and linear speed of automated industrial system drives. The suggested method is based on obtaining the optimal VFD parameters and applying them in the existing drive equipment without any changes in drive constituents. From this point of view, the results of presented study can be useful for practical application in the similar automation systems for their adjustment and performance improvement.

The most important parameter of efficiency for the automated industry processes is manufacturing lead-time [17] that is one cycle duration of the packages' transfer line.
In industrial automation systems, the OEE index, known as the multiplication of Availability, Performance, and Quality, shows the efficiency of manufacturing. In this formula, the Performance is the division of Ideal Cycle Time and Real Cycle Time. According to [19], most manufacturing companies have an OEE score between $40 \%$ and $60 \%$. The authors concluded that performance ratio depends on machine operating cycles. Therefore, practical aspects for the VFD system settings described in this paper are of current interest and benefit.

The optimal frequency and voltage for the motor found by some studies [18], [20] offer simulation models based on the complicated mathematical calculations and elaborate the design of models using MATLAB/SIMULINK software. Also, induction motor [18] was tested in laboratory conditions that cannot be compared to real conditions of the compound operating motor system with VFD. The proposed model [20] requires additional testing and VFD settings correction in order to use it in real life industrial systems.

In comparison to suggested methods in [18], [20] for obtaining optimal frequency and optimal linear speed of motor, frequencies and linear speed values were calculated at first. Each step was increased by $10 \%$, starting from $40 \%$ of the initial speed value up to $100 \%$ using simple arithmetic equations. At the second stage, the system was operated by obtaining frequency and linear speed values and measuring energy consumption under these conditions. The optimized frequency and linear speed parameters correspond to lower energy consumption by the motors. In the third step, linear equation systems evaluating energy consumption depending on the step time duration were composed in order to precise the optimized cycle duration. MATLAB software that is widely used in the scientific world was utilized to solve the equation systems. Hence, suggested methods for the efficiency optimization in industrial automated systems arranged with VFD are implemented effortlessly and provide a noticeable electricity expenditure reduction.

\section{System Structure AND PRINCIPLE OF OPERATION}

Package transportation automation line includes electric motors and frequency converters, and operates in cycle regime. The rated constants for these motors and frequency converters are presented in Table I. Each cycle includes 10 steps, which vary in length. The motors of system's electric drives operate at maximum speed and $50 \mathrm{~Hz}$ rate frequency. The capture pitchforks of the lifting mechanism move with maximum permitted speed of $0.2 \mathrm{~m} / \mathrm{s}$. The constituents of the system are shown in Fig. 1, and the operating guiding principle is described below.

In the conventional start of the cycle, the pitchforks 7 are normally raised, cart 3 is near a supplying conveyor 1 , and all electrical drives (M1, M2, and M3) are stopped. When the sensor indicates the package presence on the supplying conveyor, the rollers 6 driven by motor M1 start to rotate $\mathrm{CW}$ direction that results in package motion to the cart.

After the package is completely placed on the cart surface, the M1 motor is switched off and the cart wheels' 4 drive M2 is switched on to allow transportation of the $1^{\text {st }}$ package by the cart moving on rails 5 toward storehouse conveyor 8 . 
TABLE I. THE EQUIPMENT DRIVES' RATED PARAMETERS.

\begin{tabular}{|c|c|c|c|c|c|c|c|}
\hline \multicolumn{4}{|c|}{ Rollers drive (M1) and Cart wheel drive (M2) } & \multicolumn{4}{|c|}{ Lifting mechanism (M3) } \\
\hline \multicolumn{2}{|l|}{ Motor } & \multicolumn{2}{|c|}{ Frequency converter } & \multicolumn{2}{|c|}{ Motor } & \multicolumn{2}{|c|}{ Frequency converter } \\
\hline \multicolumn{2}{|c|}{$\begin{array}{c}\text { SEW-EURODRIVE R37 } \\
\text { DRS71M4 }\end{array}$} & \multicolumn{2}{|c|}{ Delta VFD015E43A } & \multicolumn{2}{|c|}{$\begin{array}{c}\text { Kollmorgen } \\
\text { AKM53K-NC2R-00 }\end{array}$} & \multicolumn{2}{|c|}{$\begin{array}{c}\text { Kollmorgen } \\
\text { AKD-P01206-NBCC-E000 }\end{array}$} \\
\hline Parameter & Value & Parameter & Value & Parameter & Value & Parameter & Value \\
\hline Frequency, $\mathrm{Hz}$ & 50 & Voltage, U (3-phs) & $380-480$ & Current (RMS), A & 9.1 & Input voltage, $\mathrm{V}$ & $\begin{array}{l}120(1- \\
\text { phs }) / 240(3- \\
\text { phs. })\end{array}$ \\
\hline Rotating speed, rpm & 1342 & Input current, $\mathrm{A}$ & 4.3 & $\begin{array}{l}\text { Max. rotating } \\
\text { speed, rpm }\end{array}$ & 4500 & Output voltage, V & $0-240$ \\
\hline Power, kW & 0.55 & Power, kW & $2(\approx 1.5 \mathrm{~kW})$ & Power, kW & 1.06 & $\begin{array}{c}\text { Input frequency, } \\
\mathrm{Hz}\end{array}$ & $50 / 60$ \\
\hline Voltage, U (Y) & $380-420$ & Output current, A & 4.2 & Max. torque, $\mathrm{Nm}$ & 11.25 & $\begin{array}{c}\text { Output frequency, } \\
\mathrm{Hz}\end{array}$ & $0-800$ \\
\hline Current, A & 1.62 & $\begin{array}{c}\text { Output frequency, } \\
\mathrm{Hz}\end{array}$ & $0.1-600$ & & & Current (RMS), A & 12 \\
\hline $\mathrm{PF}$ & 0.72 & & & & & $\begin{array}{l}\text { Power, kVA } \\
(240 \mathrm{~V})\end{array}$ & 3.82 \\
\hline
\end{tabular}

The cart's forward motion towards the storehouse conveyor is stopped when the safety distance is achieved between cart and lifting mechanism of pitchforks.

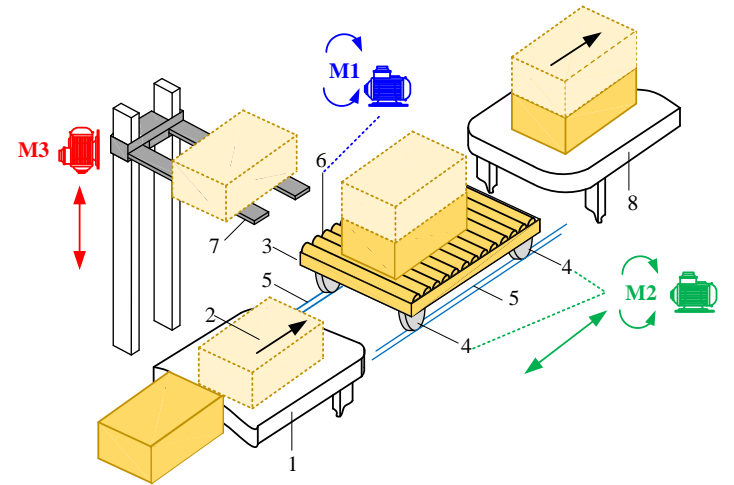

Fig. 1. The complex structure of package transportation: 1 - Supplying Conveyor (SC); 2 - Package; 3 - Cart; 4 - Cart Wheels; 5 - Rails Track; 6 - Rollers; 7 - Pitchforks of Lifting Mechanism (PLM); 8 - Warehouse Conveyor (WC); M1 - Rollers drive motor; M2 - Motor of cart wheel; M3 - Motor of Lifting Mechanism drive.

This distance is indicated by a sensor and initiates the stop of M2 electric machine, as well as of the cart 3. In the following step, the motor M3 of Pitchforks' Lifting Mechanism starts to operate and the capture pitchforks are lowered to pick up the $1^{\text {st }}$ package. The M2 motor gets a signal from height measuring sensor and cart with the $1^{\text {st }}$ package moves toward the lifting mechanism. At this moment, M2 motor rotates in CCW direction. The cart stops in such a position near the lifting mechanism that the pitchforks are placed underneath the $1^{\text {st }}$ package. At this moment, the M2 machine of cart wheels stops. After that, the M3 starts to run and the $1^{\text {st }}$ package is raised up by a lifting mechanism. At this point of time, the supplying conveyor transfers the $2^{\text {nd }}$ package. As the cart is near the supplying conveyor, the procedure is repeated: M1 electric motor starts to rotate the rollers $\mathrm{CW}$ and the $2^{\text {nd }}$ package is moved to the surface of cart. When the $2^{\text {nd }}$ package completely covers the cart surface, the lifting mechanism starts to operate again dropping the $1^{\text {st }}$ package onto the $2^{\text {nd }}$ one. When the $1^{\text {st }}$ package is successfully placed on the $2^{\text {nd }}$, the M3 machine of lifting mechanism is stopped. Finally, the M2 motor of cart wheels starts rotating CW to move two packages by rails toward warehouse conveyor.

In order to investigate the influence of stop time duration to efficiency of system, the continuance of each cycle step was measured. The cycle steps, as well as their length-time, are presented in Table II.

\section{TABLE II. OPERATION ALGORITHM AND ITS STAGES} DURATION.

\begin{tabular}{|c|c|c|c|c|c|c|c|c|c|c|}
\hline $\begin{array}{c}\text { Part of } \\
\text { cycle }\end{array}$ & \multicolumn{5}{|c|}{$\mathbf{I}^{\text {st }}$ part } & \multicolumn{5}{|c|}{ II $^{\text {nd }}$ part } \\
\hline Step No. & 1 & 2 & 3 & 4 & 5 & 6 & 7 & 8 & 9 & 10 \\
\hline 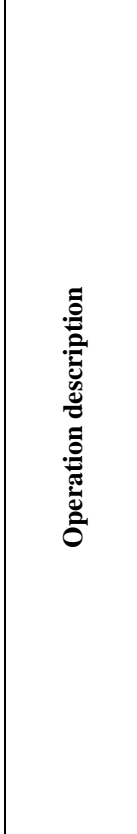 & 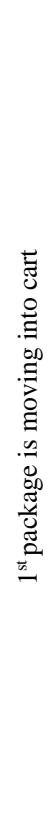 & 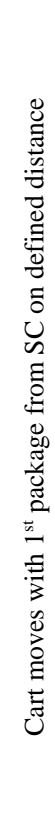 & 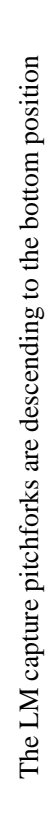 & 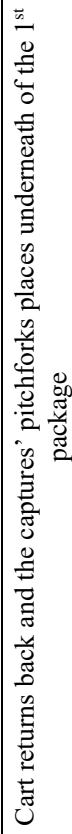 & 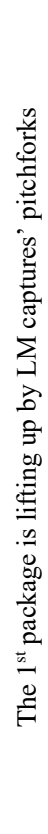 & 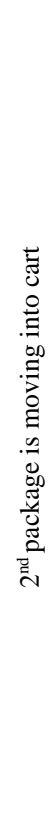 & 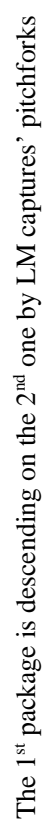 & 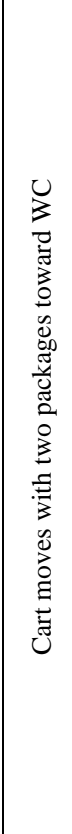 & 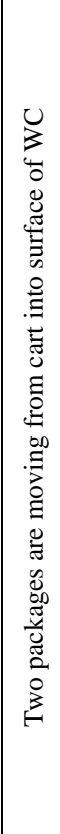 & 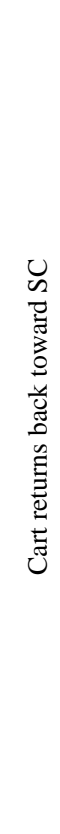 \\
\hline $\begin{array}{l}\text { Duration, } \\
\text { (s) (actual) }\end{array}$ & 5.1 & 6.1 & 6.8 & 5.5 & 6.8 & 5.0 & 1.3 & 15.1 & 9.2 & 15.1 \\
\hline $\begin{array}{c}\text { Total } \\
\text { duration } \\
\text { of cycle, }(\mathrm{s})\end{array}$ & \multicolumn{10}{|c|}{76} \\
\hline $\begin{array}{c}\text { Step } \\
\text { duration, } \\
(\%)\end{array}$ & 6.7 & 8.0 & 8.9 & 7.2 & 8.9 & 6.6 & 1.7 & 19.9 & 12.1 & 19.9 \\
\hline
\end{tabular}


It was discovered that during system operation after completing cycle steps, system stops and waits while the Supplying Conveyor will deliver a new package. In ideal operation mode, the package is placed on the cart straight away after it was put on the Supplying Conveyor.

However, under real conditions the cart is in the stopped mode. It was noticed that the cart stops its movement between $10^{\text {th }}$ and $1^{\text {st }}$ step of cycle when the $1^{\text {st }}$ package is placed on the cart, as well as between $5^{\text {th }}$ and $6^{\text {th }}$ stages of cycle when the $2^{\text {nd }}$ package is placed on the cart.

The stop time, as it is shown in Table III, varies due to the working conditions of the previous automated line equipment and additionally depends on the transported package weight.

Some type of packages are delivered faster compared to the others. The lower the speed of drives, the smaller electrical energy expenditure.

TABLE III. STOP TIME DURATION DEPENDENCY ON PACKAGE TYPE.

\begin{tabular}{|c|c|c|c|c|c|c|}
\hline Package type & $\begin{array}{c}\text { Type } \\
\mathbf{1}\end{array}$ & $\begin{array}{c}\text { Type } \\
\mathbf{2}\end{array}$ & $\begin{array}{c}\text { Type } \\
\mathbf{3}\end{array}$ & $\begin{array}{c}\text { Type } \\
\mathbf{4}\end{array}$ & $\begin{array}{c}\text { Type } \\
\mathbf{5}\end{array}$ & $\begin{array}{c}\text { Type } \\
\mathbf{6}\end{array}$ \\
\hline$t_{\min },(\mathrm{s})$ & 41.1 & 54.1 & 62.0 & 81.3 & 100.3 & 160.6 \\
\hline$t_{\max },(\mathrm{s})$ & 119.2 & 159.5 & 196.1 & 157.7 & 198.7 & 256.7 \\
\hline$t_{\text {averge }},(\mathrm{s})$ & 79.2 & 105.5 & 136.0 & 119.0 & 159.1 & 205.3 \\
\hline
\end{tabular}

Therefore, it was concluded to obtain the precise stop time of the system drives and to harmonize operating mode duration in such a way that system's equipment operation would be slowed down, so that it would result in the increase of the total system efficiency.

\section{FINDING OF OPTIMAL PARAMETERS}

As it is shown in Table II, without including the time duration between the cycle two parts: the first part (between $1^{\text {st }}$ and $10^{\text {th }}$ steps) and the second part (between $5^{\text {th }}$ and $6^{\text {th }}$ steps) of operation cycle are equal to $76.0 \mathrm{~s}$. It can be seen that $8^{\text {th }}, 9^{\text {th }}$ and $10^{\text {th }}$ time duration steps constitute to more than half of the whole cycle time, i.e., it is a time that includes cart moving time toward Storage Conveyor, package shifting from cart to SC surface and returning. According to Table III, the average smaller stop time needed to prepare package to be shifted onto cart surface is $79.2 \mathrm{~s}$ ("Type 2"), while the biggest average time is obtained for package "Type 6" when average stop time is equal to $205.3 \mathrm{~s}$.

Taking into account the possible operational faults, the optimized automation unit operation cycle should be calculated as

$$
t_{C}=t_{a v} \times k_{s}
$$

where $t_{C}$ is the optimized cycle duration, [s]; $t_{a v}$ is the average stop time between two parts of cycle, $[\mathrm{s}] ; k_{s}$ is the spare $10 \%$ factor applied for the possible operational faults, $\%$.

The continuances of the first and second cycle parts are obtained as follows:

$$
t_{I}=\sum_{i=1}^{n=5} t_{i}
$$

$$
t_{I I}=\sum_{i=6}^{n=10} t_{i}
$$

where $t_{I}$ and $t_{I I}$ - the duration of the first and the second cycle parts, respectively, $[\mathrm{s}] ; i$ is duration value corresponding to the $i^{\text {th }}$ step of the cycle, [s]; $n$ is the number of steps in the cycle part.

Therefore, taking into account that the first cycle part (from $1^{\text {st }}$ to $5^{\text {th }}$ step) of considered equipment is accomplished during 30.3 seconds, the average stop times of $1^{\text {st }}$ stand of the $2^{\text {nd }}$ cycle part are calculated as:

$$
\begin{gathered}
t_{s(I)}=t_{C}-t_{I}, \\
t_{s(I I)}=t_{C}-t_{I I},
\end{gathered}
$$

where $t_{s(I)}$ and $t_{s(I I)}$ are the average stop times over the first and second cycle parts accordingly, [s].

The total stop time over two cycle parts is obtained as

$$
t_{s}=t_{s(I)}+t_{s(I I)}
$$

Hence, the optimized duty cycle of considered automation system is expressed in percentage and evaluated

$$
t_{D T}=\frac{t_{s(I)}+t_{s(I I)}}{t_{I}+t_{I I}+t_{s(I)}+t_{s(I I)}} 100 \% .
$$

Operational times of system equipment cycles obtained using equations (1)-(7) are presented in Table IV. The equipment velocities of previous automation line could not be accelerated as they operate on the maximum speed. Therefore, operational time of the cart and pitchforks drives can be extended to $45.6 \%$ without any influence for system operation, i.e., duration time of each cycle part can be extended up to $71 \mathrm{~s}$.

TABLE IV. CYCLES AND THEIR STOP TIME DURATION

\begin{tabular}{|c|c|c|c|c|c|c|}
\hline$t_{C},(\mathbf{s})$ & $\boldsymbol{t}_{\boldsymbol{I}},(\mathbf{s})$ & $\boldsymbol{t}_{\boldsymbol{I I}},(\mathbf{s})$ & $\boldsymbol{t}_{\boldsymbol{s}(I)},(\mathbf{s})$ & $\boldsymbol{t}_{\boldsymbol{s}(I)},(\mathbf{s})$ & $\boldsymbol{t}_{\boldsymbol{s}},(\mathbf{s})$ & $\boldsymbol{t}_{\boldsymbol{D} T},(\boldsymbol{\%})$ \\
\hline 71 & 30.3 & 45.7 & 40.7 & 25.3 & 66 & 46.5 \\
\hline
\end{tabular}

The energy consumption was measured for each $n^{\text {th }}$ step of the cycle by changing operation speed of drives. The speed for electrical machines was slowed by increasing deceleration factor which value was changed by increasing each step by $10 \%$, starting from $40 \%$ of the initial speed value up to $100 \%$. The equations used for the installing frequency and linear speed calculation are presented below

$$
f_{n}=f_{n 0} \times \frac{t_{n 0}}{t_{n}}
$$

where $f_{n}$ is VFD $n^{\text {th }}$ step frequency, [Hz]; $f_{n 0}$ is drive's initial frequency, $[\mathrm{Hz}] ; t_{n}$ is the $n^{\text {th }}$ step of cycle duration time for linear motion of pitchforks, $[\mathrm{s}] ; t_{n 0}$ is $n^{\text {th }}$ step actual time values presented in Table II.

$$
v_{n}=v_{n 0} \times \frac{t_{n 0}}{t_{n}},
$$


where $v_{n}$ is $n^{\text {th }}$ step linear speed, [m/s]; $v_{n 0}$ is initial linear speed, $[\mathrm{m} / \mathrm{s}]$.

Set up parameters obtained from (8) and (9) are presented in Table V and Table VI. Their values were used for the measurement of electricity consumption by the system drives in both operation cycle parts.

The frequencies of motors' drives, as well as linear speed, were changing according to data shown in Table $\mathrm{V}$ and
Table VI and for $1^{\text {st }}$ and $2^{\text {nd }}$ cycle part, respectively. For every speed value, the energy utilization measurements were done twice. Therefore, there were 14 measurements for every cycle step.

Measurement readings were loaded to the Matlab software, and electricity consumption graphics were drawn for both cycle parts as shown in Fig. 2 and Fig. 3, respectively.

TABLE V. ADJUSTABLE PARAMETERS FOR THE ENERGY CONSUMPTION METERING OF DRIVES (PART I OF CYCLE).

\begin{tabular}{|c|c|c|c|c|c|c|c|c|c|c|}
\hline Step & \multicolumn{2}{|c|}{1} & \multicolumn{2}{|c|}{2} & \multicolumn{2}{|c|}{3} & \multicolumn{2}{|c|}{4} & \multicolumn{2}{|c|}{5} \\
\hline$k_{d}$ & $f_{1},(\mathrm{~Hz})$ & $\begin{array}{l}t_{1}, \\
\text { (s) }\end{array}$ & $f_{2},(\mathrm{~Hz})$ & $\begin{array}{l}t_{2} \\
(\mathrm{~s})\end{array}$ & $v_{3},(\mathrm{~m} / \mathrm{s})$ & $\begin{array}{l}t_{3}, \\
\text { (s) }\end{array}$ & $f_{4},(\mathrm{~Hz})$ & $\begin{array}{l}t_{4} \\
\text { (s) }\end{array}$ & $v_{5},(\mathrm{~m} / \mathrm{s})$ & $\begin{array}{l}t_{5} \\
\text { (s) }\end{array}$ \\
\hline $40 \%$ & 20 & 12.75 & 20 & 15.25 & 0.08 & 17.00 & 20 & 13.75 & 0.08 & 15.25 \\
\hline $50 \%$ & 25 & 10.20 & 25 & 12.20 & 0.10 & 13.60 & 25 & 10.00 & 0.10 & 12.20 \\
\hline $60 \%$ & 30 & 8.50 & 30 & 10.17 & 0.12 & 11.33 & 30 & 9.17 & 0.12 & 10.17 \\
\hline $70 \%$ & 35 & 7.29 & 35 & 8.71 & 0.14 & 9.71 & 35 & 7.86 & 0.14 & 8.71 \\
\hline $80 \%$ & 40 & 6.38 & 40 & 7.63 & 0.16 & 8.50 & 40 & 6.88 & 0.16 & 7.63 \\
\hline $90 \%$ & 45 & 5.67 & 45 & 6.78 & 0.18 & 7.56 & 45 & 6.11 & 0.18 & 6.78 \\
\hline $100 \%$ & 50 & 5.10 & 50 & 6.10 & 0.20 & 6.80 & 50 & 5.50 & 0.20 & 6.10 \\
\hline
\end{tabular}

TABLE VI. ADJUSTABLE PARAMETERS FOR THE ENERGY CONSUMPTION METERING OF DRIVES (PART II OF CYCLE).

\begin{tabular}{|c|c|c|c|c|c|c|c|c|c|c|}
\hline Step & \multicolumn{2}{|c|}{$\mathbf{1}$} & \multicolumn{2}{|c|}{$\mathbf{2}$} & \multicolumn{2}{|c|}{$\mathbf{3}$} & \multicolumn{2}{|c|}{$\mathbf{5}$} \\
\hline$k_{d}$ & $f_{6},(\mathrm{~Hz})$ & $t_{6},(\mathrm{~s})$ & $v_{7},(\mathrm{~m} / \mathrm{s})$ & $t_{7},(\mathrm{~s})$ & $f_{8},(\mathrm{~Hz})$ & $t_{8},(\mathrm{~s})$ & $f_{9},(\mathrm{~Hz})$ & $t_{9},(\mathrm{~s})$ & $v_{10},(\mathrm{~m} / \mathrm{s})$ & $t_{10},(\mathrm{~s})$ \\
\hline $40 \%$ & 20 & 12.50 & 20 & 3.25 & 0.08 & 37.75 & 20 & 23.00 & 0.08 & 37.75 \\
\hline $50 \%$ & 25 & 10.00 & 25 & 2.60 & 0.10 & 30.20 & 25 & 18.40 & 0.10 & 30.20 \\
\hline $60 \%$ & 30 & 8.33 & 30 & 2.17 & 0.12 & 25.17 & 30 & 15.33 & 0.12 & 25.17 \\
\hline $70 \%$ & 35 & 7.14 & 35 & 1.86 & 0.14 & 21.57 & 35 & 13.14 & 0.14 & 21.57 \\
\hline $80 \%$ & 40 & 6.25 & 40 & 1.63 & 0.16 & 18.88 & 40 & 11.50 & 0.16 & 18.88 \\
\hline $90 \%$ & 45 & 5.56 & 45 & 1.44 & 0.18 & 16.78 & 45 & 10.22 & 0.18 & 16.78 \\
\hline $100 \%$ & 50 & 5.00 & 50 & 1.30 & 0.20 & 15.10 & 50 & 9.20 & 0.20 & 15.10 \\
\hline
\end{tabular}

Using trend lines (Fig. 2 and Fig. 3) obtained during system operation simulation under different frequencies and velocity values, the equation systems were composed that evaluate energy consumption dependency on the step time duration for the both cycle parts:

$$
\left\{\begin{array}{l}
E_{1}\left(t_{1}\right)=0.00694 t_{1}^{2}-0.202 t_{1}+1.89 \\
E_{2}\left(t_{2}\right)=0.00414 t_{2}^{2}-0.172 t_{2}+2.21 \\
E_{3}\left(t_{3}\right)=0.0000308 t_{3}^{2}-0.00403 t_{3}+0.218 \\
E_{4}\left(t_{4}\right)=0.00660 t_{4}^{2}-0.205 t_{4}+2.08 \\
E_{5}\left(t_{5}\right)=0.00396 t_{5}^{2}-0.175 t_{5}+4.58
\end{array}\right.
$$

where $t_{1}, t_{2}, \ldots, t_{5}$ - the duration of $1^{\text {st }}, 2^{\text {nd }}, \ldots, 5^{\text {th }}$ step accordingly for cycle part I, $[\mathrm{s}] ; E_{1}\left(t_{1}\right), E_{2}\left(t_{2}\right), \ldots$, $E_{5}\left(t_{5}\right)-$ energy consumption at $1^{\text {st }}, 2^{\text {nd }}, \ldots, 5^{\text {th }}$ step accordingly, [Wh].

$$
\left\{\begin{array}{l}
E_{6}\left(t_{6}\right)=0.00546 t_{6}^{2}-0.169 t_{6}+1.71 \\
E_{7}\left(t_{7}\right)=0.00220 t_{7}^{2}-0.016 t_{7}+0.073 \\
E_{8}\left(t_{8}\right)=0.00137 t_{8}^{2}-0.147 t_{8}+4.79 \\
E_{9}\left(t_{9}\right)=0.00320 t_{9}^{2}-0.163 t_{9}+2.77 \\
E_{10}\left(t_{10}\right)=0.00167 t_{10}^{2}-0.140 t_{10}+3.90
\end{array}\right.
$$

where $t_{6}, t_{7}, \ldots, t_{10}$ - the duration of $6^{\text {th }}, 7^{\text {th }}, \ldots, 10^{\text {th }}$ step accordingly for cycle part II, [s]; $E_{6}\left(t_{6}\right), E_{7}\left(t_{7}\right), \ldots$, $E_{10}\left(t_{10}\right)-$ energy consumption at $6^{\text {th }}, 7^{\text {th }}, \ldots, 10^{\text {th }}$ step accordingly, [Wh].

Durations time with which the lowest amount energy is consumed were defined using equations:

$$
\begin{gathered}
t_{I}=\sum_{i=1}^{n=5} \frac{t_{i}}{k_{d}}, \\
t_{I I}=\sum_{i=6}^{n=10} \frac{t_{i}}{k_{d}} .
\end{gathered}
$$

Energy consumption during cycle parts I and II is calculated as follows:

$$
\begin{gathered}
E_{I}=\sum_{i=1}^{n=5} E_{i}, \\
E_{I I}=\sum_{i=6}^{n=10} E_{i},
\end{gathered}
$$

where $E_{I}$ and $E_{I I}$ - total energy consumed by system during cycle's parts I and II, respectively, [Wh]; $E_{i}$ is the amount of energy corresponding to the $i^{\text {th }}$ step of the cycle, [Wh].

Total energy consumption during the cycle is

$$
E_{C}=E_{I}+E_{I I}
$$




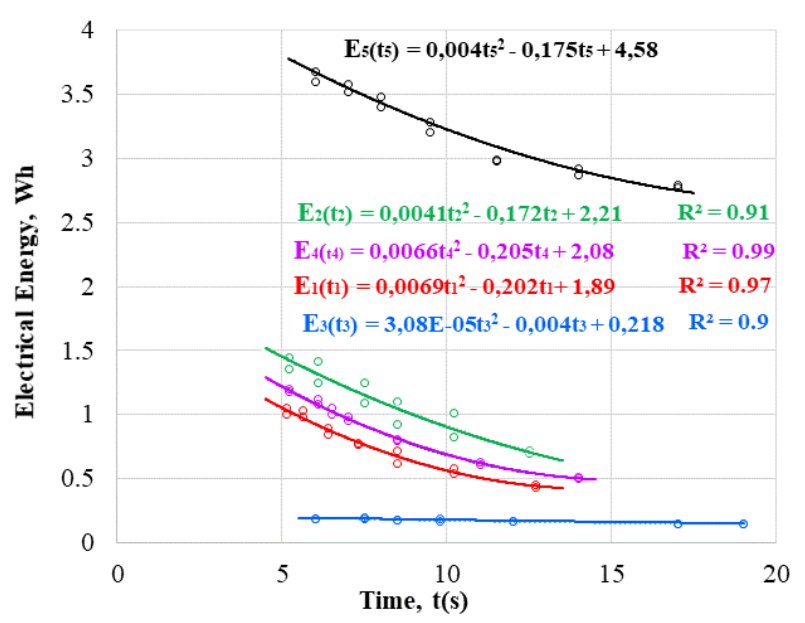

Fig. 2. Scatter diagrams of electricity consumption measurements during part I of the cycle.

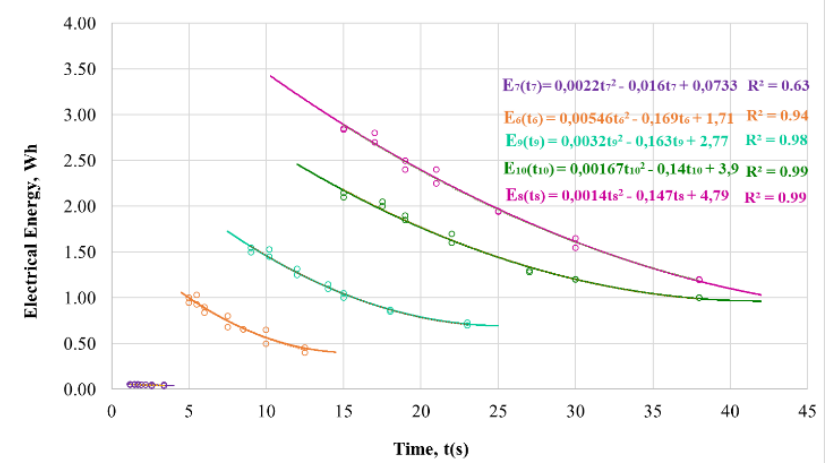

Fig. 3. Scatter diagrams of electricity consumption measurements during part II of the cycle.

\section{UTILIZED ENERGY QUANTIFICATION}

As it was discussed previously, the maximum duration value of each cycle's part should be in the range of $68 \mathrm{~s}-$ $71 \mathrm{~s}$. Following this condition, 757 and 7020 solutions (with resolution $\mathrm{R}=10$ ) and 2516 and 1669 solutions (with resolution $\mathrm{R}=50$ ) for the equation systems (10), (11) were obtained, respectively. All results are shown in Figs. 4-7. As it is shown in Fig. 4 and Fig. 6, under condition that $\mathrm{R}=10$, the obtained results are disposed within the range of 4.2 Wh-4.9 Wh and 4.0 Wh-6.5 Wh for cycle parts I and II accordingly. The ranges with the smallest electricity consumption are outlined by the red frame in the Fig. 4 and Fig. 6.

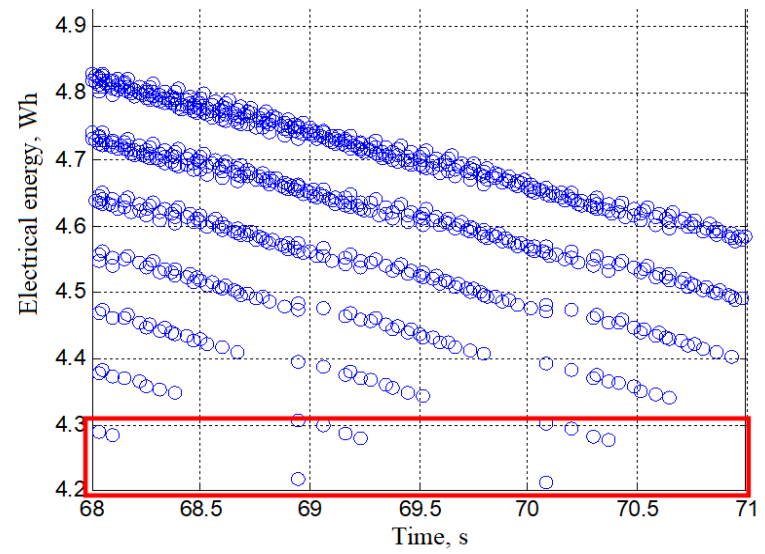

Fig. 4. Electrical energy consumption dependency on cycle duration time: cycle part $\mathrm{I},(\mathrm{R}=10)$.
To achieve more precise results, the calculations were repeated by increasing the resolution to $R=50$ and filtering all results greater than $4.2 \mathrm{Wh}$ (for the part I) and greater than 4.3 Wh (for the part II). There were 2516 and 1669 results obtained which match with the given duration range of cycle parts.

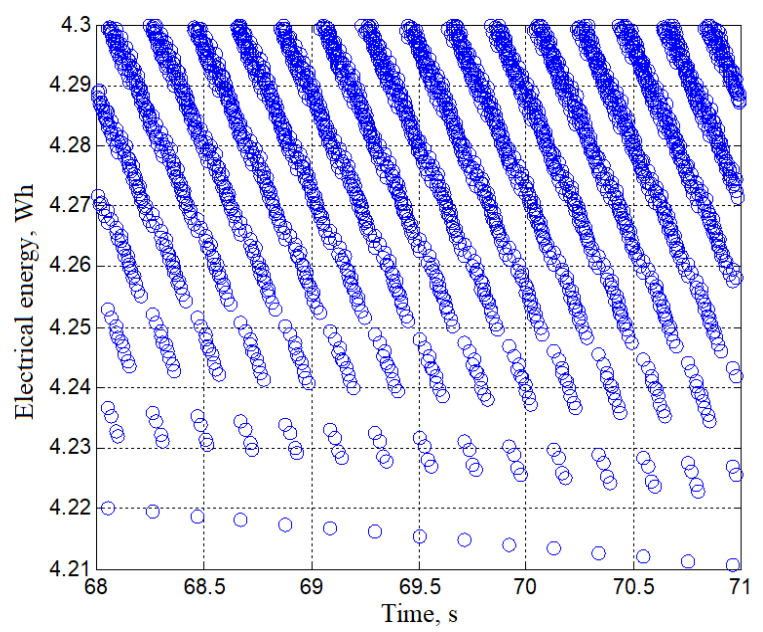

Fig. 5. Electrical energy consumption dependency on cycle duration time: cycle part $I,(R=50)$.

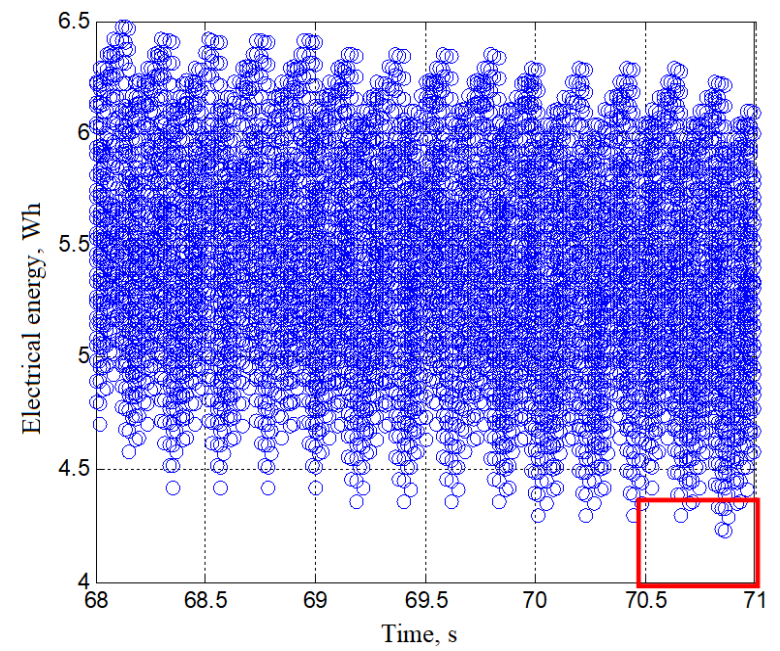

Fig. 6. Electrical energy consumption dependency on cycle duration time: cycle part II, $(\mathrm{R}=10)$.

More accurate calculations' results (when $\mathrm{R}=50$ ) are shown in Fig. 5 and Fig. 7.

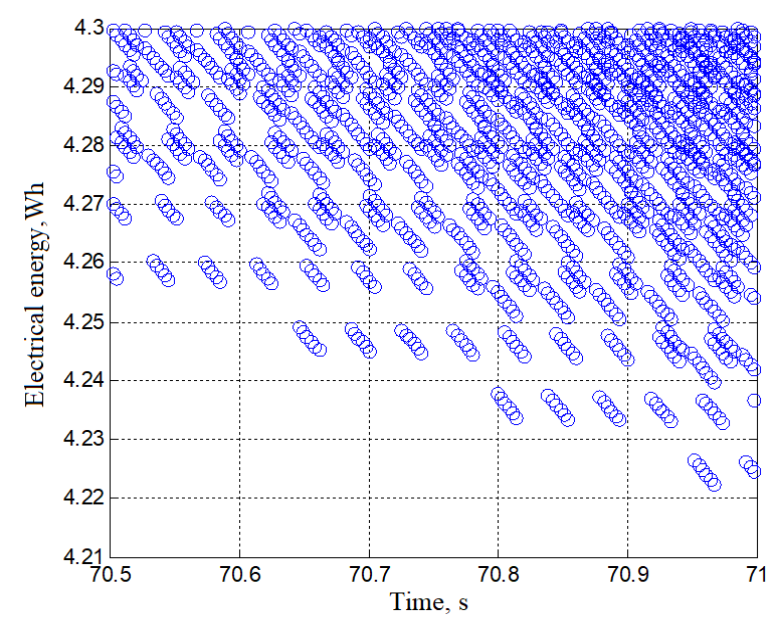

Fig. 7. Electrical energy consumption dependency on cycle duration time: cycle part II, $(\mathrm{R}=50)$. 


\section{DISCUSSION}

It was determined that the lowest power consumption in either cycle part would be if the system was operated within time intervals, as well as with defined frequencies and linear speeds that are listed in Table VII.

TABLE VII. OPTIMISED SETTING PARAMETERS OF EQUIPMENT.

\begin{tabular}{|c|c|c|c|c|}
\hline \multicolumn{5}{|c|}{ I $^{\text {st }}$ part of cycle } \\
\hline $\begin{array}{l}\text { Cycle } \\
\text { stage }\end{array}$ & $\begin{array}{c}\text { Electric } \\
\text { motor } \\
\text { designation }\end{array}$ & Time $\left(t_{n}\right), s$ & $\begin{array}{c}\text { Frequency } \\
\left(f_{n}\right)\end{array}$ & $\begin{array}{c}\text { Linear } \\
\text { speed }\left(v_{n}\right)\end{array}$ \\
\hline 1 & M2 & 12.75 & $20 \mathrm{~Hz}$ & - \\
\hline 2 & M1 & 15.25 & $20 \mathrm{~Hz}$ & - \\
\hline 3 & M3 & 12.21 & - & $0.11 \mathrm{~m} / \mathrm{s}$ \\
\hline 4 & M1 & 13.75 & $20 \mathrm{~Hz}$ & - \\
\hline 5 & M3 & 17.00 & - & $0.08 \mathrm{~m} / \mathrm{s}$ \\
\hline \multicolumn{2}{|c|}{$\begin{array}{c}\text { Total cycle's part } \\
\text { duration }\end{array}$} & 70.96 & & \\
\hline \multicolumn{5}{|c|}{ II ${ }^{\text {nd }}$ part of cycle } \\
\hline $\begin{array}{l}\text { Cycle } \\
\text { stage }\end{array}$ & $\begin{array}{c}\text { Electric } \\
\text { motor } \\
\text { designation }\end{array}$ & Time $\left(t_{\mathrm{n}}\right), \mathrm{s}$ & $\begin{array}{c}\text { Frequency } \\
\qquad\left(f_{\mathrm{n}}\right)\end{array}$ & $\begin{array}{c}\text { Linear } \\
\text { speed }\left(v_{n}\right)\end{array}$ \\
\hline 6 & M2 & 5.31 & $47 \mathrm{~Hz}$ & - \\
\hline 7 & M3 & 1.30 & - & $0.2 \mathrm{~m} / \mathrm{s}$ \\
\hline 8 & M1 & 27.41 & $28 \mathrm{~Hz}$ & - \\
\hline 9 & M2 & 9.20 & $50 \mathrm{~Hz}$ & - \\
\hline 10 & M1 & 27.75 & $27 \mathrm{~Hz}$ & - \\
\hline \multicolumn{2}{|c|}{$\begin{array}{c}\text { Total cycle's part } \\
\text { duration }\end{array}$} & 70.97 & & \\
\hline
\end{tabular}

These optimized frequencies and linear speeds were obtained using (8), (9).

Optimized parameters, presented in Table VII, were applied to the equations (10) and (11) systems that allow to define the values of minimums of electrical energy consumption in the system during the cycle.

The comparative values of the system energy consumption before and after optimization are shown in Table VIII.

TABLE VIII. OPTIMISED SETTING PARAMETERS OF EQUIPMENT.

\begin{tabular}{|c|c|c|c|c|}
\hline \multirow{2}{*}{} & \multicolumn{4}{|c|}{ Energy expenditures measurements, (Wh) } \\
\cline { 2 - 5 } & $\mathbf{1}$ & $\mathbf{2}$ & $\mathbf{3}$ & $\begin{array}{c}\text { Average } \\
\text { value }\end{array}$ \\
\hline $\begin{array}{c}\text { Before } \\
\text { optimisation }\end{array}$ & 14.23 & 14.83 & 14.07 & 14.38 \\
\hline $\begin{array}{c}\text { After } \\
\text { optimisation }\end{array}$ & 8.83 & 8.52 & 8.79 & 8.71 \\
\hline Calculated value & \multicolumn{5}{|c|}{8.51} \\
\hline
\end{tabular}

It was found that if the first cycle part duration would be 70.96 seconds, the system would operate consuming 4.21 Wh of energy per cycle. Also, if the operational time of the second part cycle would be $70.97 \mathrm{~s}$, the system would consume 4.22 Wh of energy per cycle.

The total energy consumption during operational time was calculated using (16). System parameters were reinstalled using data shown in Table VIII, newly obtained data and the energy consumption were measured.

\section{CONCLUSIONS}

The efficiency of industrial processes' energy consumption decreases by monitoring, measuring, and optimizing system parameters, such as frequency of electrical drive and its linear speed. The optimization of these parameters allows saving about $60 \%$ of energy per cycle.

During this study, it was found that $46.5 \%$ of operational time is uselessly wasted when waiting for the next package, and it was calculated that the operational time of each of two cycle parts could be extended to $71 \mathrm{~s}$. It was obtained that in order to improve efficiency the system should complete the first part of the cycle in $70.96 \mathrm{~s}$ and consume $4.21 \mathrm{Wh}$ of electricity. The second part of the cycle should be completed in $70.97 \mathrm{~s}$ and consume $4.22 \mathrm{Wh}$ of electricity. The optimized power consumption of the system is $8.51 \mathrm{Wh}$ per cycle. The estimated average power consumption of a newly set system is $8.71 \mathrm{Wh}$, which is only $2.4 \%$ error of mathematical calculations' results in comparison with measured power values. The method provided in this study is applicable as a good practice to investigate other industrial processes.

\section{CONFLICTS OF INTEREST}

The authors declare that they have no conflicts of interest.

\section{REFERENCES}

[1] E. Z. Barie and Ch.-k. Chang, "Application of variable frequency drive on the condensate pump motors of APR1400 nuclear power plants for energy savings", Journal of International Council on Electrical Engineering, vol. 8, no. 1, pp. 178-188, 2018. DOI: 10.1080/22348972.2018.1515691.

[2] J. Lim, M. S. Yoon, T. Al-Qahtani, and Y. Nam, "Feasibility study on variable-speed air conditioner under hot climate based on real-scale experiment and energy simulation", Energies, vol. 12, no. 8, p. 1489 , 2019. DOI: 10.3390/en12081489.

[3] M. Kassas, W. M. Hamanah, O. Al-Tamimi, A. Sahin, B. S. Yilbas, and C. B. Ahmed, "Operation of HVAC system for energy savings and economic analysis", Journal of Thermal Engineering, vol. 5, no. 3, pp. 181-197, 2019. DOI: 10.18186/THERMAL.541072.

[4] A. D. Gaikwad, "Energy conservation using VFD", International Journal of Innovative Research in Advanced Engineering, vol. 2, no. 1, pp. 130-133, 2015.

[5] P. Bhase and M. Lathkar, "Energy conservation using VFD", in Proc. of 2015 International Conference on Energy Systems and Applications, Pune, 2015, pp. 531-536. DOI: 10.1109/ICESA.2015.7503406.

[6] G. Carabin, E. Wehrle, and R. Vidoni "Review on energy-saving optimization methods for robotic and automatic systems", Robotics, vol. 6 , no. 4 , p. 39, 2017. DOI: $10.3390 /$ robotics6040039.

[7] P. K. Choudhary and S. P. Dubey, "Efficiency optimization of induction motor drive at steady-state using artificial neural network", World Journal of Modelling and Simulation, vol. 13, no. 2, pp. 94104, 2017

[8] V. K. A. Shankar, S. Umashankar, S. Paramasivam, and H. Norbert "Real time simulation of Variable Speed Parallel Pumping system", Energy Procedia, vol. 142, pp. 2102-2108, 2017. DOI: 10.1016/j.egypro.2017.12.612.

[9] Md. E. Hoque, F. Rashid, M. Y. Prodhan, and A. Arman "Analysis of energy consumption and efficiency to reduce power losses in industrial equipment", in Proc. of International Conference on Mechanical Engineering (ICME 2017), 2017, pp.1-7.

[10] A. Sukhanov, G. Yang, Y. Jichao, O. Perelman, and N. Derkach, "Enhancement of electric submersible pump energy efficiency by replacing an inductive motor with a permanent magnet motor", Oil Gas European Magazine, vol. 44, no. 3, pp. 146-150, 2018. DOI: $10.19225 / 180906$.

[11] S. Hesari, M. Noruziazghandi, A. A. Shojaei, and M. Neyestani, "Investigating the intelligent methods of loss minimization in induction motors", Telkomnika (Telecommunication Computing Electronics and Control), vol. 16, no. 3, pp.1034-1053, 2018. DOI: 10.12928/TELKOMNIKA.v16i3.8293.

[12] C. B. Venkatramanan and S. Padma, "Automatic power factor and speed control of three phase induction motor using programmable logic control", International Journal of Engineering \& Technology, vol. 7, no. 2.8, pp. 533-538, 2018. DOI: 10.14419/ijet. v7i2.8.10516. 
[13] S. Hesari and M. B. N. Sistani, "Efficiency improvement of induction motor using fuzzy-genetic algorithm", in Proc. of 2015 30th Power System Conference (PSC), 2015, pp. 210-216. DOI: 10.1109/IPSC.2015.7827750.

[14] M. Jufer, Electric Drives: Design Methodology. John Wiley \& Sons, Inc., 2013. DOI: 10.1002/9781118622735.

[15] K. K. Tan and A. S. Putra, Drives and Control for Industrial Automation. Springer-Verlag London Limited, 2011. DOI: 10.1007/978-1-84882-425-6.

[16] A. Hughes and B. Drury, Electric Motors and Drives: Fundamentals, Types and Applications, 4th ed. Newness, 2013. DOI: 10.1016/B9780-08-098332-5.00004-8.

[17] P. Barosz, G. Gołda, and A. Kampa, "Efficiency analysis of manufacturing line with industrial robots and human operators",
Applied Science, vol. 10, no. 8, p. 2862, 2020. DOI 10.3390/app10082862.

[18] M. P. Sruthi, C. Nagamani, and G. S. Ilango, "An improved algorithm for direct computation of optimal voltage and frequency for induction motors", Engineering Science and Technology, vol. 20, no. 5, pp. 1439-1449, 2017. DOI: 10.1016/j.jestch.2017.11.007.

[19] G. Gołda, A. Kampa, and I. Paprocka, "Modelling and simulation of manufacturing line improvement", International Journal of Computational Engineering Research (IJCER), vol. 6, no. 10, pp. 2631, 2016.

[20] E. Omorogiuwa and Ch. Ayor, "Energy efficiency optimization of three phase induction motor drives for industrial applications", International Journal of Engineering and Applied Sciences (IJEAS), vol. 5, no. 8, 2018. DOI: 10.31873/IJEAS.5.8.20.

This article is an open access article distributed under the terms and conditions of the Creative Commons Attribution 4.0 (CC BY 4.0) license (http://creativecommons.org/licenses/by/4.0/). 